\title{
The Effect of a Training Program Using Speed-Specific Strength Exercises on Sensory-Motor Perception in Learning Stroke Forehand Smash in Badminton Material for Students of the Hashemite University
}

\author{
Mahmoud Al - Haliq \\ College of Physical Education and Sport Sciences, Hashemite University, Jordan
}

Received July 20, 2020; Revised November 6, 2020; Accepted November 29, 2020

\section{Cite This Paper in the following Citation Styles}

(a): [1] Mahmoud Al-Haliq, "The Effect of a Training Program Using Speed-Specific Strength Exercises on Sensory-Motor Perception in Learning Stroke Forehand Smash in Badminton Material for Students of the Hashemite University," International Journal of Human Movement and Sports Sciences, Vol. 8, No. 6, pp. 299 - 307, 2020. DOI: 10.13189/saj.2020.080601.

(b): Mahmoud Al-Haliq (2020). The Effect of a Training Program Using Speed-Specific Strength Exercises on Sensory-Motor Perception in Learning Stroke Forehand Smash in Badminton Material for Students of the Hashemite University. International Journal of Human Movement and Sports Sciences, 8(6), 299 - 307. DOI: 10.13189/saj.2020.080601.

Copyright $\odot 2020$ by authors, all rights reserved. Authors agree that this article remains permanently open access under the terms of the Creative Commons Attribution License 4.0 International License

\begin{abstract}
Purpose: This study aims at identifying the effect of a training program using speed-specific strength exercises on sensory-motor perception in learning stroke forehand smash in badminton material for students of the Hashemite University. Methodology: Using experimental design, 40-badminton course students consisted the sample of this study, as they were chosen intentionally, and were divided into two equal groups (control, experimental). The instruments used to measure sensory-motor perception were; dynamometer, stopwatch, ruler, tape measure, and blindfold, as well as, badminton rackets, shuttlecock, rubber cord, extra pillars badminton "213 cm high", and stripy court for testing to measure skill performance. Data were analyzed using SPSS version 21 (SPSS, Inc., Chicago, IL, USA). Findings: The results showed that there was a lack of a positive effect of the traditional program on improving sensory-motor perception and learning stroke forehand smash skills of both types of badminton skills in tests: ruler, grip strength, and jump 60. Meanwhile, there was a positive impact of the traditional program on improving sensory-motor perception and learning stroke forehand smash skills, of both types of badminton skills in tests: watch, stroke forehand smash, and stroke forehand smash with a jump, and a positive impact of the
\end{abstract}

experimental program on improving sensory-motor perception and learning forehand smash skills, of both types of badminton in all test skills. Contribution and Recommendation: This research contributes to both types of badminton in all test skills, by making the speed-specific strength exercises as sports training program.

Keywords Training Program, Speed-Specific Strength, Perceptions Sensory-Motor, Forehand Smash, Badminton

\section{Introduction}

The sports movement has witnessed rapid development recently. These developments resulted from the core changes that occurred in most games, whether on the laws level or on the state (physical, skill, planning, psychological, and mental) that player should enjoy. Which in turn reflected on achieving the best in many sporting achievements. The exercise is an effective tool for the trainer to achieve the required educational and training goal. For this, the training unit should consist of a set of exercises through which the desired goal can be achieved [1-2]. 
Any mathematical movement requires a certain degree of muscular strength, a period of time, and extent. The interaction of these variables leads to saving effort, energy, and quality of motor performance. Therefore, the kinetic sense of strength means the athlete's ability to demonstrate the appropriate amount of muscle strength needed for specific motor performance. As for a kinesthetic, sense of time is the athlete's ability to determine the time of movement or effectiveness. Concerning a kinetic sense of distance, it is the athlete's ability to determine the distance covered during performance [3].

What distinguishes a badminton game, is the convergence of mental abilities with physical abilities. The game depends on elements of strength, speed as well as other fitness elements. While, badminton weight requires large strength in the forehand smash. It is performed through mental ability, big burden and participation of the muscles, balance nervous and muscular systems, which in turn leads the player to mastery of the skill [4].

Perception of sensory-motor is important in the game of badminton through a sense of muscle effort, resistance, and speed of movement. For that, the player should possess a high ability to perceive numerous variables such as distance, time, strength, and direction. However, developing these variables will help identifying most of the stimuli that the player faces, and enable him/her to choose the appropriate response to the situation. [5-6].

Because of its frequent use, the importance of this study lies in raising the performance of offensive movements (forehand smash). Moreover, it was noticed that there is a lack of interest and focus among various of teachers on sensory-motor perception within the curricula of skills education. So, a training program containing exercises with a characteristic repetition and continuity was suggested, where it enables the added strength to be utilized during the transition process between body parts. Adding to that, the possibility of employing it on demand and the ability to benefit from it in reducing excessive tensile movements help to involve large torso muscles, arms, and forearm. Which in turn provides the appropriate speed and strength for performing forehand smash.

\subsection{Problem Statement}

Movement effectiveness is not lacking in the absence of the basic variables (distance - strength - time). Thus, the fitness components are an indication of the player's success in the field of badminton. The teacher or coach who plans to utilize the training programs can develop the physical and skill performance of the player. Most teachers use two-third of the preparation for the skill part, but unfortunately, they neglect the special physical abilities in the training unit [7-8].

Teaching badminton and following up the educational units brought my attention that most students have weakness in some perceptions of sensory-motor, such as distance, time, and direction. Consequently, it affects the speed of the kinetic response and accuracy in the implementation of the forehand smash. The fact that the learning process is an important and auxiliary factor in identifying stimuli and their perception, in order to create motor programs within the brain, which makes the response quicker. From this standpoint, the problem of the study revolved that there is a need to develop a proposed training program using speed-specific strength, to measure its effect on the development of work of perception sensory-motor - forehand smash skill in badminton game.

\subsection{Research Objectives}

The objectives of this study are as follows:

(a) Identifying the differences between pre and post measurement of the control group members, to improve the performance of sensory-motor perception and learning the stroke forehand smash skill of both types in badminton.

(b) Identifying the Differences between pre and post measurement of the experimental group members, to improve the performance of sensory-motor perception and learning the stroke forehand smash skill of both types in badminton.

(c) Identifying the differences between the experimental and control groups in telemetry, to improve the performance of sensory-motor perception and learning the stroke forehand smash skill of both types in badminton.

\subsection{Research Hypotheses}

(a) There are statistically significant differences between the pre and post measurements of the control group members, in improving the performance of sensory-motor perception, learning the stroke forehand smash skill of both types in badminton for the favor of telemetry.

(b) There are statistically significant differences between the pre, post measurements of the experimental group members, in improving the performance of sensory-motor perception, learning the stroke forehand smash skill of both types in badminton for the favor of telemetry.

(c) There are statistically significant differences in post-measurement between the control and experimental groups, in improving the performance of sensory-motor perception, learning the stroke forehand smash skill of both types in badminton, for the favor of the experimental group.

\subsection{Research Terminology}

(a) Training speed-specific strength: are special exercises in the pilot program; contain a set of 
exercises (for the upper and lower extremities), with the aim of improving the individual's ability to accomplish in the least possible time [9].

(b) Sensory-motor perception: is the sensation that enables athletes to determine the position of the body, state of its extension, the direction of movement, which is the state of the overall position of the body, and the characteristics of movement [10].

(c) Kinetic sense of strength means: is the athlete's ability to demonstrate the appropriate amount of muscle strength, required for a specific kinetic performance such as; showing the maximum strength, medium, or low [11].

(d) The kinesthetic sense of time: is the athlete's ability to determine the time of movement or effectiveness [12].

(e) Kinetic sensation of distance: is the ability to determine the distance traveled during performance [13].

The stroke forehand smash skills of both types in badminton: are a variety of offensive strokes carried out on the badminton court rectangle, in order to score a point in order to win [14].

\section{Literature Review}

(Khuwaila and Al-Jaafra, 2016) Conducting a study entitled "The Effect of a Proposed Fitness Program for Table Tennis on Improving Some Perceptual Variables Motor, Skill Performance". Using the experimental method, the study sample consisted of 33 students from the Faculty of Sports Sciences at Mu'tah University, which were intentionally chosen. Where, the experimental and control sample consisted of 16 students. The duration of the program was 8 weeks, by two training units per week. Then perceptual motor variables were measured before and after the proposed program. However, the results revealed statistically significant differences in improving fitness level, and a decrease in the error of estimating the variables (perception of kinesthetic time, sense of distance, sense of strength, skill level) for the favor of the experimental group. [15].

(Abdel-Hussein et al, 2015) carried a study on the title of "The Effect of The Diversity of Variable and Fixed Practice in Developing Sensory-Motor Perception Response Speed and Accuracy of The Forehand and Backhand Drop in Badminton Skills of Players 11-13 Years". The experimental method in designing (the two equivalent groups with pre- and post-test) was used. While, the sample represents 16 players of ages between 11-13, and were divided into two groups. The first group was trained by changing practice, while, the second was trained by fixed practice. The most important findings were that the sensory-motor perception exercises and rapid response helped in developing the accuracy of the forehand and the backhand drop-in badminton skills. Recommendations stressed on training in kinetic response speed exercises, due to their necessity in badminton, and the need to pay attention to complex exercises between perceiving stimuli and responding to them in open and fixed environments, because most badminton skills require multiple responses [5].

(Hardan \& Hudhayfah, 2013) conducted a study aimed at identifying the relationship between agility and the explosive ability of the two arms precisely, by the skill of the stroke smash of the badminton. The sample consisted of 20 students from the third stage of the college of the physical education. The researchers assumed that there was a statistically significant correlation between agility and the explosive ability of the arms, with the precision of the stroke smash of the badminton. But they found that the agility and explosive power of the arms affect the accuracy of the smash with the feather [6].

(Muhammad et al., 2012) directed a study aimed at identifying the relationship between the sensory-motor perception with the accuracy of the performance of some offensive movements in the fencing sport, for students of physical education. The researchers assumed a significant relationship between the study variables. Thus, the descriptive method was used, while, the study sample is formed from 29 third-stage students of the college of sports education of the University of Qadisiyah. A form was designed to solicit expert opinions in this field to determine offensive skills and sensory-motor abilities. However, the results reveal that there is a correlation between sensory abilities and offensive skills. [16].

(Jihad, 2009) carried a study entitled "Applying Some Plyometric Exercises to Develop Explosive Force and Kinetic Speed and Its Impact on The Skill of Smash Stroke of The Badminton". The experimental method in designing the two groups was used. The sample consisted of 12 players from the excellent class clubs-youth category. Performing the statistical analysis and discussing the results, the study showed the plyometric exercises that are similar in their motor path to the skill path, work towards developing the technical performance of the skill. Accordingly, recommendations asserted on the necessity of integrating the plyometric exercises with the training curriculum designed to develop physical traits for athletes. [14].

(Sushil et al, 2015) undertook a study to evaluate the effect of playing badminton on the reaction time. The aim of the study is to compare visual reaction times of badminton players with those of age-matched controls. The researchers estimated the visual reaction times of 50 male badminton players of 18-22 years age group, who were practicing badminton for $2-3 \mathrm{~h} /$ day for a minimum of 2 years. The visual reactions were compared with those of 50 age-matched healthy male students of Dr. SCGMC 
Nanded (Maharashtra, India), who formed the control group. The results of the visual reaction time of dominant as well as a non-dominant limb of badminton players was significantly less than those of the control group, who were not practicing any sports activity. The conclusion of the study has supported the view that playing badminton is beneficial in improving the eye-hand reaction time, muscle coordination, cognitive functions, concentration, and alertness [17].

(Zhu Q, 2013) stated that affordances mean opportunities for action. These affordances are important for sports performance and relevant to the abilities developed by skilled athletes. In racquet sports such as badminton, different players prefer widely different string tension, because it is believed to provide opportunities for effective strokes. Hence, the current study examined whether badminton players can perceive the affordance of string tension for power strokes and whether the perception of affordance itself changed as a function of skill level. The results showed that string tension constrained the striking performance of both novice and recreational players, but not of expert players. But when perceptual capability was assessed, the perceptual mode did not affect the perception of the optimal string tension. While, skilled players successfully perceived the affordance of string tension, but only experts were concerned about saving energy. The However, findings demonstrated that the perception of the affordance of string tension in badminton was determined by action abilities. Furthermore, experts could adjust the action to maintain a superior level of performance based on the perception of affordance [18].

\section{Materials and Methods}

\subsection{Research Design}

In this research, the experimental design was used. All participants voluntarily participated in this research. The study was designed to identify the effect of a training program using speed-specific strength exercises on sensory-motor perception in learning stroke forehand smash, in badminton material for students of the Hashemite University.

The duration of the proposed training program was 8 weeks, by three training units per week. The time of each training unit was 45 minutes, where training unit involve general and special warm-up exercises. Thus, the training program is used to implement speed-specific strength exercises. The traditional and the experimental programs were implemented as shown in tables 1,2, and 3 .

Table 1. Traditional program for the control group

\begin{tabular}{ccccc}
\hline Week & $\begin{array}{c}\text { General and } \\
\text { Special } \\
\text { Warm-up }\end{array}$ & $\begin{array}{c}\text { Main Part } \\
\text { Skill } \\
\text { Preparation }\end{array}$ & $\begin{array}{c}\text { Closing } \\
\text { Part }\end{array}$ & Total \\
\hline $1-2$ & $10 / \mathrm{m}$ & $30 / \mathrm{m}$ & $5 / \mathrm{m}$ & $45 / \mathrm{m}$ \\
$3-4$ & $10 / \mathrm{m}$ & $30 / \mathrm{m}$ & $5 / \mathrm{m}$ & $45 / \mathrm{m}$ \\
$5-6$ & $10 / \mathrm{m}$ & $30 / \mathrm{m}$ & $5 / \mathrm{m}$ & $45 / \mathrm{m}$ \\
$7-8$ & $10 / \mathrm{m}$ & $30 / \mathrm{m}$ & $5 / \mathrm{m}$ & $45 / \mathrm{m}$ \\
\hline
\end{tabular}

Dimensional measurements of the tests (for sensory-motor perception, stroke forehand smash test, and stroke forehand smash test with a jump), were taken in the badminton, between February 20, and April 20, 2018.

Table 2. The proposed experimental program for the experimental group

\begin{tabular}{cccccc}
\hline Week & $\begin{array}{c}\text { General and Special } \\
\text { Warm-Up }\end{array}$ & $\begin{array}{c}\text { Main Par } \\
\text { Speed-Specific Strength } \\
\text { Exercises }\end{array}$ & Skill Preparation & $\begin{array}{c}\text { Closing } \\
\text { Part }\end{array}$ & Total \\
\hline $1-2$ & $5 / \mathrm{m}$ & $15 / \mathrm{m}$ & $20 / \mathrm{m}$ & $5 / \mathrm{m}$ & $45 / \mathrm{m}$ \\
$3-4$ & $5 / \mathrm{m}$ & $15 / \mathrm{m}$ & $20 / \mathrm{m}$ & $5 / \mathrm{m}$ & $45 / \mathrm{m}$ \\
$5-6$ & $5 / \mathrm{m}$ & $15 / \mathrm{m}$ & $20 / \mathrm{m}$ & $5 / \mathrm{m}$ & $45 / \mathrm{m}$ \\
$7-8$ & $5 / \mathrm{m}$ & $30 / \mathrm{m}$ & $5 / \mathrm{m}$ & $5 / \mathrm{m}$ & $45 / \mathrm{m}$ \\
\hline
\end{tabular}

Table 3. The time period, training load components, intensity, repetition, rest periods, number of groups, and rest periods between groups

\begin{tabular}{clccccc}
\hline Week & Load Components & Intensity & Repetition & Rest Periods & $\begin{array}{c}\text { Number of } \\
\text { Groups }\end{array}$ & $\begin{array}{c}\text { Rest Periods } \\
\text { between } \\
\text { Groups }\end{array}$ \\
\hline $1-2$ & Aforementioned exercise & intermediate & $5-3$ & $30 / \mathrm{sec}$ & $4-3$ & $60 / \mathrm{sec}$ \\
$3-4$ & Aforementioned exercise & High & $8-4$ & $45 / \mathrm{sec}$ & $3-2$ & $90 / \mathrm{sec}$ \\
$5-6$ & Aforementioned exercise & intermediate & $5-3$ & $30 / \mathrm{s}$ & $4-3$ & $60 / \mathrm{sec}$ \\
$7-8$ & Aforementioned exercise & High & $8-4$ & $45 / \mathrm{sec}$ & $3-2$ & $90 / \mathrm{sec}$ \\
\hline
\end{tabular}




\subsection{Research Subject}

The study population consisted of 60 students from the badminton course, where, 40 feather course students were chosen intentionally. They were divided into two equal groups:-control and experimental as shown in table 4.

Table 4. Distribution of the study sample

\begin{tabular}{cc}
\hline Groups & Number of participants \\
\hline $\begin{array}{c}\text { Control group: used the traditional } \\
\text { training program }\end{array}$ & 20 \\
$\begin{array}{c}\text { Experimental group: used the demo } \\
\text { training program. }\end{array}$ & 20 \\
Total & 40 \\
\hline
\end{tabular}

\subsection{Research Instrument}

The tribal tests were conducted to confirm the equivalence between the control and experimental groups in the sensory-motor perception tests, and learned stroke forehand smash in the skill of both types in badminton as shown in table 5.

Table 2 shows the statistical results of the study variables (stroke forehand smash, sensory-motor perception tests). It reveals that all calculated (T) values for the difference between the control and experimental group were limited and were (1.000-2.060). Which are non-statistically significant values compared to the Table (T) value. This indicates that the two groups are equal in all skills.

In this research, the measuring tools and devices were used related to the following measurements and tests:
Dynamometer, stopwatch, ruler, tape measure, and blindfold to measure sensory-motor perception [19-20]. Also, badminton rackets, shuttlecock, rubber cord, extra pillars badminton " $213 \mathrm{~cm}$ high", and stripy court for testing to measure skill performance.

Before applying for the training program, perception tests - sensory-motor were defined as measuring grip strength $50 \%$ - perceiving the distance $10 \mathrm{~cm}$ with a ruler - bouncing to a distance of $60 \mathrm{~cm}$ - perceiving time $10 / \mathrm{s}$. In addition, skill performance tests were defined as stroke forehand smash test and stroke forehand smash test with a jump.

The study tool was validated through a group of specialists in the fields of (physical education, sports training, and badminton). They were the ones passed the tests after proposing some modifications to it (sensory-motor perception, skill tests). Applying the test and re-applying it to a sample of 10 students from the study community, the stability of the tests (sensory-motor perception, learning the skill of the stroke forehand smash and stroke forehand smash with a jump) in the badminton was calculated.

\subsection{Analyze Data}

SPSS statistical program version 21 (SPSS, Inc., Chicago, IL, USA) was used to process data. While mean, standard deviation, median, Pearson correlation coefficient, test $(\mathrm{T})$ between the pre and post measurements of each group, and the two groups' post measurement were extracted accordingly.

Table 5. Arithmetic mean, standard deviations, and $(\mathrm{T})$ value of the study variables in the pre-measurement between the two groups

\begin{tabular}{|c|c|c|c|c|c|c|}
\hline Skill & Groups & $\mathbf{N}$ & $\mathbf{M}$ & SD & Value (T) & Sig. \\
\hline \multirow{2}{*}{ Stroke smash } & Control & 20 & 13.50 & 5.08 & \multirow{2}{*}{-1.921} & \multirow{2}{*}{0.062} \\
\hline & Experimental & 20 & 17.10 & 6.66 & & \\
\hline \multirow{2}{*}{ Stroke smash with jump } & Control & 20 & 10.65 & 3.79 & \multirow{2}{*}{-1.773} & \multirow{2}{*}{0.085} \\
\hline & Experimental & 20 & 13.35 & 5.66 & & \\
\hline \multirow{2}{*}{ Ruler } & Control & 20 & 3.04 & 0.76 & \multirow{2}{*}{-2.120} & \multirow{2}{*}{0.053} \\
\hline & Experimental & 20 & 2.28 & 1.41 & & \\
\hline \multirow{2}{*}{ grip strength } & Control & 20 & 2.33 & 1.39 & \multirow{2}{*}{1.000} & \multirow{2}{*}{0.100} \\
\hline & Experimental & 20 & 2.33 & 1.25 & & \\
\hline \multirow{2}{*}{ Jump $60 / \mathrm{cm}$} & Control & 20 & 8.17 & 3.11 & \multirow{2}{*}{1.312} & \multirow{2}{*}{0.197} \\
\hline & Experimental & 20 & 6.90 & 3.01 & & \\
\hline \multirow{2}{*}{ Watch } & Control & \multirow{2}{*}{20} & 1.47 & 0.66 & \multirow{2}{*}{2.060} & \multirow{2}{*}{0.057} \\
\hline & Experimental & & .0 .98 & 0.86 & & \\
\hline
\end{tabular}


Table 6. Arithmetic Averages, Standard Deviations, and (T) Test between Pre and Post Measurements of Control Panel $(\mathrm{N}=20)$

\begin{tabular}{|c|c|c|c|c|c|c|c|}
\hline \multirow{2}{*}{ Skills } & \multicolumn{2}{|c|}{ pre-measurement } & \multicolumn{2}{|c|}{ post-measurement } & \multirow{2}{*}{ MD } & \multirow{2}{*}{ Value (T) } & \multirow{2}{*}{ SIG } \\
\hline & M & SD & M & SD & & & \\
\hline Stroke smash & 3.039 & 0.758 & 2.929 & .9229 & .1100 & 1.725 & 0.101 \\
\hline Stroke smash with jump & 2.330 & 1.392 & 2.395 & 1.074 & -0.065 & -0.264 & .7940 \\
\hline Ruler & 8.172 & 3.106 & 8.550 & 5.404 & -0.376 & -0.350 & .7300 \\
\hline grip strength & 1.274 & .6570 & 1.448 & 0.615 & .2260 & 3.258 & .0040 \\
\hline Jump $60 / \mathrm{cm}$ & 10.650 & 3.787 & 12.100 & 3.127 & -0.750 & -2.445 & .0240 \\
\hline Watch & 13.500 & 5.084 & 14.250 & 5.118 & -1.450 & -4.125 & .0010 \\
\hline
\end{tabular}

The significance value was set at $\alpha \leq 0.05$.

\section{Results and Discussion}

\subsection{The First Hypothesis}

There were statistically significant differences between the pre and post measurements of the members of the control group, in improving the performance of the sensory-motor perception, learn the stroke forehand smash test, and stroke forehand smash test with a jump badminton for the favor of the post measurement. Table 6 illustrates this.

Table (6) shows the values of the arithmetic averages (M), Standard deviations (SD), and the calculated value of (T), for the pre and post control group members measurements in the sensory-motor and skill tests in the badminton. The values of (T) were (0.264-4.125) which is less than the tabular value (T). The results also showed that there were no statistically significant (SIG) differences in the skills (ruler, grip strength, Jump $60 / \mathrm{cm}$ ) between the two pre-measurements of the control group.

These results attributed to the weakness of the traditional training program; whose application focused on the skill side of the badminton. If we look at the traditional training program shown in Table (3), we would observe that most of training period unit time is focused on the skill side, where the public and private physical preparation program did not improve the level of sensory-motor perception. Hence, the results of this study were consistent with (Jaber, 2001) study [7], which confirmed that the traditional training program did not improve the level of sensory-motor perception. Vice versa, the results of this study were inconsistent with (Abu Al Fotouh, 1997) study
[21], which confirms that the special physical program has improved the level of sensory-motor perception.

The results also showed that there were statistically significant differences in the skills (watch, stroke forehand smash, and stroke forehand smash with the jump), between the two pre-measures of the control group and in the favor of post- measures.

The reason is attributed to the improvement of the control group members, in the telemetry to the method of implementing the traditional program that focused on skills performance training. Being in mind that any training program may have an impact on improving skill performance, especially if the study sample consisted of beginners, therefore, the traditional program improved the performance of the members of the control group in skills badminton. The results of this study agreed with (Abdul Rahman, 1997) study [22], where it proved that the traditional training program improved the level of performance of the control group in badminton skills. Likewise, the results of this study agreed with (Abdul Rahman, 1997) study [22], and (Zidane, 2010) study [1], in that the traditional training program improves the level of performance of the stroke smash in badminton.

\subsection{The Second Hypothesis}

There were statistically significant differences between the pre and post - measurements of the members of the experimental group in improving the performance of sensory-motor perception and learn the stroke smash in badminton for the favor of post- measures. Table 7 illustrates this: 
Table 7. Arithmetic Averages, Standard Deviations, and (T) Test between Pre and Post Measurements of experimental $(\mathrm{N}=20)$

\begin{tabular}{|c|c|c|c|c|c|c|c|}
\hline \multirow[t]{2}{*}{10.5} & \multicolumn{2}{|c|}{ Pre-Measurement } & \multicolumn{2}{|c|}{ Post-Measurement } & \multirow{2}{*}{ MD } & \multirow{2}{*}{ Value $(\mathrm{T})$} & \multirow{2}{*}{ SIG } \\
\hline & M & SD & M & SD & & & \\
\hline Stroke Smash & 2.279 & 1.412 & 1.251 & 2.104 & .1750 & 1.330 & .1990 \\
\hline Stroke Smash with Jump & 2.330 & 1.252 & 1.990 & 1.022 & .3400 & 2.066 & .0530 \\
\hline Ruler & 6.903 & 3.012 & 4.675 & 2.637 & 2.228 & 8.296 & 0.000 \\
\hline Grip Strength & .9760 & 0.860 & .5090 & .5560 & .4670 & 6.237 & 0.000 \\
\hline Jump $60 / \mathrm{Cm}$ & 17.100 & 6.664 & 19.700 & 5.957 & -2.600 & -4.398 & 0.000 \\
\hline Watch & 13.350 & 5.659 & 20.250 & 4.930 & -6.900 & -10.990 & 0.000 \\
\hline
\end{tabular}

The significance value was set at $\alpha \leq 0.05$.

Table 8. Arithmetic means, standard deviations, and ( $T$ ) value of the study variables in the post measurement between the two groups

\begin{tabular}{ccccccc}
\hline \multirow{2}{*}{ Skills } & \multicolumn{2}{c}{ Control group } & \multicolumn{2}{c}{ Experimental group } & Value (T) & SIG \\
& $\mathrm{M}$ & $\mathrm{SD}$ & $\mathrm{M}$ & $\mathrm{SD}$ & & \\
\hline Ruler & 2.129 & .9230 & 2.904 & 1.2509 & -2.373 & .0230 \\
Grip Strength & 1.990 & 1.074 & 2.395 & 1.0218 & -1.222 & .8610 \\
Jump 60/Cm & 4.675 & 5.404 & 8.550 & 2.637 & 2.882 & 0.006 \\
Watch & 0.509 & .6150 & 1.248 & .5560 & 3.986 & .0010 \\
Stroke Smash & 14.250 & 5.118 & 19.700 & 5.957 & -3.103 & 0.004 \\
Stroke Smash with Jump & 12.100 & 3.127 & 20.250 & 4.930 & -6.243 & 0.000 \\
\hline
\end{tabular}

The significance value was set at $\alpha \leq 0.05$.

Table (7) shows the calculated mean values, the standard deviations, the calculated (T) value for the pre and post measurements of the experimental group members in the sensory-motor perception, as the cognitive tests in badminton. The values of (T) were (1.330-8.296), which is less than the value of the $(\mathrm{T})$ tabular. The results showed that there were statistically significant differences in all skills between the pre and post measurements of the experimental group and for the favor of the post measurement.

These results are due to the experimental program associated with the effect of the training program on the speed-specific strength exercises; which is the ability of the muscular nervous system to produce movement with the least possible time, where it contributed to improving the neuromuscular compatibility. Nevertheless, its ability to determine the distance, direction and height of the movement and exercises focused on the upper and lower limbs extremities of the body, which are determined by intensity: repetitions, rest periods using the training program, the main component of sensory-motor perception is the Muscular sensation of muscles.

The results of this study were consistent with the results of the study of (Jaber, 2011; Jaber, 2007; Abu Al Fotouh, 1997; Hamada, 1990; Hussein, 1986) [7, 21, 23,24], where special physical preparation and the use of speed-specific strength exercises improves the level of sensory-motor perception.

The study of (Al-Naimat, 1997; Abdul Rahman, 1997) $[20,22]$ indicates that educational situations become more successful, if the nervous system and sensory perception benefit from training to reach the best improvement in the player's abilities in motor performance, within the least time. This confirms that the proposed experimental training program had a strong impact in improving the performance of the stroke smash skill.

\subsection{The Third Hypothesis}

There were statistically significant differences in dimensional measurement between the control and experimental groups, in improving the performance of sensory motor perception and learning the stroke forehand smash skill of both types in badminton and for the favor of experimental group. Table 8 illustrates this.

Table (8) shows the values of the arithmetic mean, Standard deviations, the calculated value of $(T)$, for the post measurement between the control and experimental groups in the sensory-kinesthetic and skill tests in the badminton. The values of $(\mathrm{T})$ were (1.222-6.243) which is less than the tabular value (T). Thus, the results showed that there were statistically significant differences of all skills in the post measurement between the control and experimental groups and for the favor of the experimental group.

The reason for having these results refers to the fact that the members of the experimental group underwent a thoughtful program (speed-specific strength exercises miscellaneous); which contributed to the improvement of sensory-motor perception, compared to the traditional program for the control group members (which focused on the skill side). 
The results of this study were consistent with the study (Hussein, 1986; Al-Jabini, 1990; Jaber, 2011; Ahmed \& Abdul-Razzaq, 2000) [24, 25, 7, 2].

Specialists believe that the improvement of the badminton skill performance among the experimental group members compared to the control group members, is due to the distribution of the proposed training program parts (general and special warm-up, speed-specific strength exercises, skill performance, and the final activity). This is shown in Table (4), compared to the program Traditional (general and special warm-up, skill performance, and closing activity), as shown in Table (3). The study of (Abdul Raouf, 2000; Khattabi, 1988; Khalil, 1996) [27-29] confirmed that the program led to an enhancement in the Skill performance of the badminton. The results of this study were consistent with the results of the study of both (Abu Al-Fotouh, 1997; Abdul Rahman, 1997; Jaber, 2007) $[21,22,19]$, in the existence of a relationship between sensory-motor perception and some badminton skills.

\section{Conclusions}

In light of the statistical treatments, and after interpreting the results, the researcher reached the following conclusion:

a). The lack of a positive effect of the traditional program on improving sensory-motor perception and learning stroke forehand smash skills of both types of badminton (ruler, grip strength, jump 60).

b). A positive impact of the traditional program on improving sensory-motor perception and learning stroke forehand smash skills of both types of badminton (watch, stroke smash, stroke smash with jump).

c). A positive impact of the experimental program on improving sensory-motor perception and learning stroke forehand smash in all skills of both types of badminton.

\section{Recommendations}

According to the results gained, the researcher recommends the following:

a). Using the proposed training program by speed-specific strength exercises, as it showed improvement in sensory-motor perception and learning the two-stroke forehand smash skills of both types of plane badminton.

b). Carrying out similar studies on speed-specific strength exercises, applying other variables and skills of badminton.

c). Carrying out studies on different age groups to apply the speed-specific strength exercises for badminton.

\section{Acknowledgements}

The researcher acknowledges the Hashemite University for the financial Support.

\section{REFERENCES}

[1] Zidan, K. (2010). The effect of kinetic transport exercises in developing the performance of the skills of stroke smash and defensive distance with a badminton for juniors. Unpublished Master Thesis, College of Basic Education, Diyala University.

[2] Radwan, M. (2006). Introduction to measurement in physical education. Egypt: The Book Center for Publishing.

[3] Ali, A. (1993). The effect of suggested exercises to develop sensory-motor perception on the accuracy of strokes serve in tennis, Unpublished Master Thesis Faculty of Physical Education Port Said, Suez Canal University.

[4] Al-Khalaf, M. (2001). The effect of a training program with different speed feathers on developing badminton skills. Baghdad: Unpublished PhD thesis, University of Baghdad.

[5] Abdel. H., Wissam, S., Ali, A., \& Jassim, Z. (2015). The effect of the diversity of variable and fixed practice on developing sensory-motor perception, response speed and accuracy stroke forehand and backhand drop badminton players (11-13) years, University Journal of Karbala, 15, 104-118.

[6] Hardan, M., \& Khalil, H. (2013). The relationship of agility and the explosive power of a striking arm with the accuracy of a stroke smash of badminton. Journal of Physical 2, 6, 226-247.

[7] Jaber, A. (2011). The Effect of Ballistic Training with Weights Approach on Explosive Power Improvement, Attention Focus and the Accuracy of Smash Hits in Volleyball. Dirasat: Educational Sciences, 38.6, 1947-1965.

[8] Azab, A., \& Taher, M. (2015). Building a physical test battery to pick badminton players ages 14-17. Journal of the College of Physical Education, 27, 2, 15-33 University of Baghdad.

[9] Vladimir, L., Kazimierz, M., Przemysław, B., Ryszard, L. (2014). Review of Platonov's "Sports Training Periodization. General Theory and its Practical Application" - Kiev: Olympic Literature, 2013. Journal of Human Kinetics. 9, 44, 259-263.

[10] Altalb, N. (1993). Sports psychology. Baghdad: Dar Al-Hekma for Printing and Publishing.

[11] Abdel, M., \& Samer, M. (2013). Kinetic Learning and its Applications in Physical Education and Sports. Dar Al-Kutub Al-Alami, Beirut Lebanon.

[12] Ibrahim, M. A. (2000). Motor learning in the sports field, ( ${ }^{1 s t}$ edition.). Venus International Publishing Corporation.

[13] Ali, J. (2008). Physiological foundations of the movement's activities, Cairo: Dar Al-Kitab for Publishing. 
[14] [14] Jihad, S. (2009). Applying some plyometric, exercises to develop explosive strength and kinetic speed and its effect on the skill of the stroke smash of badminton. Unpublished Master Thesis, College of Physical Education, University of Baghdad.

[15] Khwaila, Q., \& Al-Jaafara, S. (2016). The effect of a proposed fitness program for table tennis on improving some variables of Sense-motor perception and skill performance, Dirasat: Educational Sciences, 43, 3, 1337-1352.

[16] Muhammad, A., Salman, H., \& Khudair, G. (2012). The relation of Sense-motor perception with the accuracy of the performance of some offensive movements with the weapon of blade for students of the Faculty of Physical Education. Al-Qadisiyah Journal of Physical Education Sciences, 12, 1, 227-244.

[17] Sushil, P. D.; Shreechakradhar, U. M.; \& Mukund, B. K. (2015). Simple visual reaction time in badminton players. A comparative study National Journal of Physiology, Pharmacy \& Pharmacology, 5, 1, 18-20.

[18] Qin Zhu. (2013). perceiving the affordance of string tension for power strokes in Badminton: Expertise allows effective use of all string tensions. Journal of Sports Sciences, 31, 11, $1187-1196$.

[19] Jaber, A. (2007). The effect of speed-specific strength exercises on sensory-motor perception and learning some volleyball skills. Humanities and Social Sciences Series, 22, 4,237-258, Mu'tah University.

[20] Al-Naimat, A. (1995). The relationship between sensory-motor perception variables and the level of skill performance on women's gymnastics for female students of the Faculty of Physical Education at the University of Jordan. Unpublished $\mathrm{PhD}$ thesis, University of Jordan.

[21] Abu Al-Fotouh, k. S. (1997). Developing a special preparation to perform smash serve skill for volleyball beginners. Unpublished Master Thesis, College of Physical Education for Boys, Zagazig University.
[22] Abdel-Rahman, E. (1997). The effectiveness of the biometric training at the distance of the vertical jump and its impact on the stroke smash and some physical capabilities of volleyball, Scientific Journal of Physical Education, 12, 77-95. Faculty of Physical Education for Girls, Alexandria University.

[23] Hamada, G. (1990). Sensory-motor perception and physical and skill performance in handball. Cairo: Predictive Study, Journal of Science, Arts and Sports, 13, 95-115, College of Physical Education for Girls.

[24] Hussain, A. (1986). The effect of some exercises to develop sense-motor perceptions on the level of performance in gymnastics. Unpublished $\mathrm{PhD}$ thesis, Haram College of Physical Education for Boys.

[25] Al-Jabini, S. (1990). Scale of fear in swimming for students of the Faculty of Physical Education. The First Scientific Conference - The Role of Physical Education in Solving Contemporary Problems, 1,240-268. College of Physical Education, Zagazig University.

[26] Ahmed, H. \& Medhat, A. R. (2000). The effect of developing some sensory-motor perceptions on the accuracy of the basketball target. The Scientific Journal of Physical and Sports Education, 2, 63-80. Faculty of Physical Education, Helwan University.

[27] Abdel Raouf, S. (2000). Relationship of some sensory-motor abilities with the accuracy of some types of punches for young boxers. Scientific Journal of Physical and Sports Education, 22, 169-185. Helwan University.

[28] Khattabi, A. (1988). Sense-motor perception and relationship to skill level for high-level players in volleyball. Comprehensive Physical Education Research, 9, 35-52, Faculty of Physical Education for Girls, Zagazig University.

[29] Khalil, H. (1996), some sense-motor perceptions relationship to the serve smash of volleyball players. Unpublished Master Thesis, College of Physical Education, Port Said. Suez Canal University. 